\title{
Prolactin delays hair regrowth in mice
}

\author{
A J Craven, A J Nixon, M G Ashby, C J Ormandy ${ }^{1}$, K Blazek ${ }^{1}$, R J Wilkins ${ }^{2}$ and A J Pearson \\ AgResearch Ruakura, Private Bag 3123, Hamilton 2020, New Zealand \\ ${ }^{1}$ Cancer Research Program, Garvan Institute of Medical Research, Darlinghurst, New South Wales, 2010 Sydney, Australia \\ ${ }^{2}$ University of Waikato, Hamilton 2020, New Zealand \\ (Requests for offprints should be addressed to A J Craven; Email: tony.craven@agresearch.co.nz)
}

\begin{abstract}
Mammalian hair growth is cyclic, with hair-producing follicles alternating between active (anagen) and quiescent (telogen) phases. The timing of hair cycles is advanced in prolactin receptor (PRLR) knockout mice, suggesting that prolactin has a role in regulating follicle cycling. In this study, the relationship between profiles of circulating prolactin and the first post-natal hair growth cycle was examined in female $\mathrm{Balb} / \mathrm{c}$ mice. Prolactin was found to increase at 3 weeks of age, prior to the onset of anagen 1 week later. Expression of PRLR mRNA in skin increased fourfold during early anagen. This was followed by upregulation of prolactin mRNA, also expressed in the skin. Pharmacological suppression of pituitary prolactin advanced dorsal hair growth
\end{abstract}

by 3.5 days. Normal hair cycling was restored by replacement with exogenous prolactin for 3 days. Increasing the duration of prolactin treatment further retarded entry into anagen. However, prolactin treatments, which began after follicles had entered anagen at 26 days of age, did not alter the subsequent progression of the hair cycle. Skin from PRLR-deficient mice grafted onto endocrine-normal hosts underwent more rapid hair cycling than comparable wild-type grafts, with reduced duration of the telogen phase. These experiments demonstrate that prolactin regulates the timing of hair growth cycles in mice via a direct effect on the skin, rather than solely via the modulation of other endocrine factors.

Journal of Endocrinology (2006) 191, 415-425

\section{Introduction}

Hair growth in mammals is not continuous. Instead, hair follicles cycle through successive phases of active hair growth (anagen), involution (catagen) and quiescence (telogen) (Muller-Rover et al. 2001). The reactivation of follicles to start a new anagen phase is characterised by the reinitiation of cell proliferation in the secondary hair germ, regeneration of the lower half of the follicle and growth of a new hair. In mice, successive generations of hairs are held in the follicle for some time before the older shafts are shed (exogen) (Milner et al. 2002). Also in mice, hair follicle cycling is synchronised, with waves of hair regrowth commencing in the axillae and progressing ventro-dorsally before reaching the head and tail. The timing of these synchronised cycles is age-related, but varies with sex and strain (Muller-Rover et al. 2001).

Hair follicle cycling is influenced by a variety of hormones (Ebling et al. 1991, Alonso \& Rosenfield 2003), including the pituitary hormone prolactin. Prolactin receptors (PRLR) have been localised to hair follicles (Craven et al. 2001) and expression of mRNAs encoding one long (PRLRL) and two short forms of the receptor (PRLRS2 and PRLRS3) have been demonstrated in murine skin. Furthermore, the concentration of these receptors varies with follicular activity (Foitzik et al. 2003). PRLR knockout mice grow slightly longer hair and moult at a younger age than wild-type littermates, indicating that prolactin signalling is involved in the timing of progression through the hair cycle phases (Craven et al. 2001). However, the secretion of other hormones, including oestrogen, progesterone and parathyroid hormone $(\mathrm{PTH})$, is xalso altered in PRLR knockout mice (Bole-Feysot et al. 1998, Clement-Lacroix et al. 1999). Oestrogen (Oh \& Smart 1996, Chanda et al. 2000) and PTH (Schilli et al. 1997) have been implicated previously in hair cycle regulation. Thus, it remains unclear whether the advanced hair cycle phenotype of PRLR knockout mice is mediated directly by the loss of prolactin signalling within hair follicles or indirectly by perturbation of other hormones.

Few studies have directly assessed the effect of exogenous prolactin on hair growth. Organ cultured hair follicles spontaneously enter a catagen-like state, and this process is accelerated by added prolactin (Foitzik et al. 2003). However, only in vivo models are presently capable of representing other phases of the hair cycle. Mohn (1958) reported that both spontaneous and plucking-induced follicle growth was unchanged following i.m. injections of prolactin to rats. Similar observations had been made following injections of crude prolactin extracted from pig and ox pituitaries (Emmens 1942). Conversely, in a number of other species, hair follicle cycling is governed by seasonal changes to produce a summer and winter moult, and prolactin has been implicated as the principal endocrine regulator of this process 
(Martinet et al. 1984, Loudon et al. 1989, Dicks et al. 1994, Pearson et al. 1996, Thompson et al. 1997). In recent years, it has become apparent that the method of prolactin administration and the resulting hormone profile are critical in determining the physiological response of hair follicles (McCloghry et al. 1993, Soboleva et al. 2005). The time at which prolactin is administered is also important, suggesting that follicles may be sensitive to prolactin at only some phases of the growth cycle. Furthermore, prolactin itself is expressed in the skin and regulated during the follicle growth cycle (Foitzik et al. 2003). Both locally produced and systemic prolactin will contribute to the concentration of prolactin to which receptors are exposed.

In this study, we aimed to elucidate the influence of prolactin on the timing of follicle cycle phases in mice. First, we characterised prolactin signalling activity in the skin of $\mathrm{Balb} / \mathrm{c}$ mice, as indicated by plasma prolactin concentrations, and expression of PRLR variants and prolactin $\mathrm{mRNA}$ in the skin leading up to the growth of the second generation of coat hairs. Secondly, pituitary prolactin secretion was suppressed with bromocriptine (BRC), and exogenous prolactin administered to regulate profiles of circulating prolactin. These treatments altered follicle growth cycles and identified a period of prolactin responsiveness during the telogen phase. Thirdly, we established that prolactin exerts an effect directly on the skin. Mouse skin lacking PRLRs was grafted onto mice with normal hormone levels. Accelerated follicle cycling was seen in transplanted skin, consistent with the phenotype of the unoperated PRLR knockout. This result demonstrates that prolactin directly affects hair cycling mechanisms within the skin.

\section{Materials and Methods}

\section{Experimental animals}

Inbred female Balb/c mice and PRLR knockout mice (Ormandy et al. 1997) were housed at the Ruakura Small Animal Colony, Hamilton, New Zealand and fed a diet of standard mouse pellets and fresh tap water available ad libitum. They were maintained at a constant temperature of $22^{\circ} \mathrm{C}$ under a photoperiod regime of 14 light:10 darkness. Mice were housed in family groups until the progeny were weaned at 21-22 days of age into groups of 4-6 mice. The experimental procedures were carried out with the approval of the Ruakura Animal Ethics Committee in accordance with the New Zealand Animal Welfare Act (1998).

\section{Profiles of circulating prolactin and PRLR $m R N A$ in skin}

Concentrations of prolactin in blood plasma and of mRNA encoding PRLR and prolactin in dorsal skin were determined in 54 untreated $\mathrm{Balb} / \mathrm{c}$ mice of post-natal ages varying between 15 and 39 days. At 3-day intervals, groups of four mice were anaesthetised with $\mathrm{CO}_{2}$ and their blood was sampled by heart puncture just prior to euthanasia by cervical dislocation. This blood was collected into EDTA-containing syringes and centrifuged to separate plasma, which was then stored frozen $\left(-20{ }^{\circ} \mathrm{C}\right)$. Dorsal and axillary skin was fixed in phosphatebuffered $10 \%$ formalin for histological assessment of hair follicle growth stage (Nixon 1993). Additional dorsal skin from each animal was snap frozen in liquid nitrogen for measurement of prolactin and PRLR mRNA by quantitative PCR.

\section{Hormone manipulations}

Circulating prolactin was pharmacologically manipulated in the period preceding and during the growth of the second generation of hair (G2). A group of mice receiving no hormonal treatment (control; $n=8$ ) was compared with groups of mice whose endogenous pituitary prolactin was suppressed using s.c. pellets releasing $250 \mu \mathrm{g} /$ day of bromocriptine mesylate for up to 60 days (Innovative Research of America Inc., Sarasota, FL, USA). These BRC implants were surgically inserted at 15 days of age $(n=6)$ or 22 days of age $(n=4)$.

Ovine prolactin $(500 \mu \mathrm{g} /$ day $)$ dissolved in sodium bicarbonate buffer $(0 \cdot 2 \mathrm{M} ; \mathrm{pH}$ 9) was administered via osmotic mini-pumps (Alzet Model 1003D, 1001 or 1002; Alza Corporation, Palo Alto, CA, USA) to groups of BRCtreated mice ( $n=2-4$ per group). The prolactin administration commenced at 18, 22 or 26 days of age and lasted for 3 or 14 days after which time osmotic pumps were removed. The BRC implants remained in place for the duration of the experiment. At the end of each treatment period, the osmotic pumps were removed and a blood sample was collected from the tail. Following completion of hair regrowth, blood was collected from all animals.

Three further mice received domperidone (Sigma Chemical Co.) via an osmotic pump $(1.8 \mathrm{mg} / \mathrm{kg}$ per day; dissolved in polyethylene glycol 400 at a concentration of $20 \mathrm{mg} / \mathrm{ml}$ ), to induce a sustained increase in endogenous pituitary prolactin secretion. The mice received domperidone from 18 to 30 days of age and were compared with three untreated littermates.

\section{Assessment of hair growth}

To monitor hair growth patterns, the coats of all mice in the hormone manipulation experiments were dyed black at 22-26 days of age, when all hair follicles were in telogen (Craven et al. 2001). Subsequent pelage growth was ascertained by daily visual examination for the presence of new, unstained hairs. Records were made of the age at which hair first emerged from axillary skin (where the wave of new hair growth across the body commences) and dorsal skin (a site commonly reported in other studies). To assess whether the age of weaning influenced hair cycling, comparisons in hair regrowth were also made between untreated siblings weaned at 18 or 24 days of age ( $n=3$ per group). 
The distribution of hair cycle stages among follicles in untreated $\mathrm{Balb} / \mathrm{c}$ mice was determined by histomorphology (Nixon 1993, Muller-Rover et al. 2001). Skin sections were stained by the Sacpic method (Nixon 1993), and at least 30 longitudinally sectioned follicles were assessed from each of three mice for each age from 24 to 39 days. To establish precisely the time at which cell proliferation within the follicle bulb commences, proliferating cell nuclear antigen (PCNA) immunohistochemistry was performed on sections from four mice per day of age (from days 18-24 for axillary skin; days 25-30 for dorsal skin). Sections of formalin-fixed skin tissue were washed in citrate buffer ( $\mathrm{pH} 6 \cdot 0 ; 10 \mathrm{~min}$ ), and blocked in PBS/4\% BSA/ Tween for $2 \mathrm{~h}$ prior to overnight incubation with monoclonal anti-PCNA antibody (Clone PC10; Dako Corporation, Carpinteria, CA, USA.) diluted in the ratio of $1 / 500$ in antibody diluent (Dako Corporation). After three washes with PBS, these sections were incubated for $1 \mathrm{~h}$ with streptavidinhorseradish peroxidase conjugated goat anti-mouse IgG (Dako Corporation) diluted in the ratio of 1:100 in antibody diluent. After further PBS washes, sites of antibody binding were visualised with diaminobenzidine (Sigma Chemical Co.) intensified with $\mathrm{H}_{2} \mathrm{O}_{2}$ and $\mathrm{NiCl}_{2}$ solution. Follicles exhibiting more than three PCNA positive cells per section in the bulb epithelium were considered to have entered anagen.

Follicles were categorised as either telogen (short follicles with no PCNA staining), anagen I (short follicles and PCNA positive), anagen II (enlarged bulb starting to form a proliferating germinal matrix), anagen III (formation of redstaining inner root sheath and hair cone), anagen IV-V (formation of picrophilic keratinised hair shaft) or anagen VI where the new hair tip has emerged from the epidermis (Nixon 1993, Parry et al. 1995).

\section{Radioimmunoassays}

Murine prolactin was assayed using rabbit antiserum to murine prolactin (National Institute of Diabetes and Digestive and Kidney Diseases (NIDDK) mouse prolactin RIA kit; reagents AFP-6476C; AFP-10777D and AFP131078; Torrance, CA, USA). Murine prolactin was iodinated by the iodogen technique (Pierce, Rockford, IL, USA), using $\left[{ }^{125} \mathrm{I}\right]$ iodide (New England Nuclear, Wilmington, DE, USA). The assay method was essentially as prescribed for the NIDDK reagents. The separation of the antibody-bound label was by secondary antibody precipitation using excess sheep anti-rabbit serum (generated at AgResearch, Hamilton, New Zealand). Sensitivity using murine prolactin standards was $1 \mathrm{ng} / \mathrm{ml}$. Intra-assay coefficient of variation was $13 \cdot 4 \%$.

Ovine prolactin was assayed using an ovine prolactin assay (NIDDK ovine prolactin RIA kit) (Nixon et al. 1993). Sensitivity using ovine prolactin standards was $0.6 \mathrm{ng} / \mathrm{ml}$. Intra-assay coefficient of variation at $90 \mathrm{ng} / \mathrm{ml}$ was $13 \cdot 7 \%$. Cross-reactivity between murine and ovine prolactin was low; using the ovine RIA, $<1 \mathrm{ng} / \mathrm{ml}$ was measured in mouse plasma containing $30 \mathrm{ng} / \mathrm{ml}$ murine prolactin or in standard solutions of $100 \mathrm{ng} / \mathrm{ml}$ murine prolactin.

\section{PRLR and prolactin gene expression}

Total RNA was extracted using TRIzol (Invitrogen Corporation), and DNA was removed using RNase-free DNase I (DNA-free Kit, Ambion, Austin, TX, USA). First, strand cDNA was generated by reverse transcription (RT) with random hexamer primers, using the Superscript II Preamplification System (Invitrogen) according to the manufacturer's instructions.

Real-time PCR was carried out using TaqMan (PRLRL, prolactin and 18S rRNA) or SYBR Green (PRLRS2 and PRLRS3) reaction mixes and the ABI PRISM 7900HT Sequence System and Sequence Detection System 1.6 software (Applied Biosystems, Foster City, CA, USA). Primers and probes used were as previously reported (Craven et al. 2001) with the exception of a more efficient PRLRL reverse primer (5'-CTCGTCCTCATTGTCATCCACTT-3'). PCR reactions using $0 \cdot 25 \mu \mathrm{l}$ of the $\mathrm{RT}$ reaction product were performed in triplicate, with results compared with a standard curve. The expression of $18 \mathrm{~S}$ rRNA was used as internal control according to the manufacturer's guidelines (Eukaryotic $18 \mathrm{~S}$ rRNA PDAR, Applied Biosystems). Levels of mRNA are reported relative to the overall experimental mean for each analysed gene.

\section{Grafting PRLR knockout skin onto scid host mice}

Skin for grafting was obtained from four 24-day old homozygous PRLR knockout mice on a $129 \mathrm{~Sv}$ background strain (Ormandy et al. 1997, Craven et al. 2001), and from four littermates or closely related mice that were wild type for PRLR. Explants of shaved scapular skin $(2 \times 10 \mathrm{~mm})$ were prepared in Dulbecco's modified Eagle's medium (DMEM) with $10 \%$ foetal calf serum and grafted onto 5 -week old NOD-scid host mice of corresponding sex. Ten host mice each carried two grafts on their scapular regions, one of each donor genotype. The grafts were sutured and covered with bandages for 14 days. Hair growth began in some grafts at 17 days after surgery. Pigmented hairs growing from donor skin contrasted with the white coats of the host mice, allowing new hair growth in the grafts to be seen. The graft sites were clipped to skin level $(<0.5 \mathrm{~mm})$ during the growing phase at 7-day intervals (males) or 10-11-day intervals (females), or as necessary to permit measurement of growth increments. The lengths of dark hairs arising from the two graft sites, and from the surrounding host skin, were recorded at 2-3-day intervals until 89 days after surgery, and the durations of hair growth from PRLR knockout and wildtype grafts were compared.

\section{Statistical analysis}

Prolactin RIA, PRLR and prolactin mRNA quantitative PCR and hair growth observational data were compared by pairwise Student's $t$-tests or one-way ANOVA. The data are presented as group means and S.E.M. 


\section{Results}

Hair cycling, plasma prolactin and gene expression in untreated Balb/c mice

The timing of progression through the hair cycle phases was determined in unmanipulated wild-type $\mathrm{Balb} / \mathrm{c}$ mice. Histological analysis showed that the first anagen terminated at 17-19 days in the dorsal skin. Following a brief telogen phase, the second anagen began with cell division in the hair bulb (anagen I), initially in the axilla. In this region, $45 \%$ of follicles exhibited increased PCNA immunostaining in hair bulb epithelial cells ( $>3$ cells per section) at 22 days of age. On the dorsum, $36 \%$ of follicles were PCNA positive at day 26 , bulb enlargement and structural reorganisation (anagen II) was first observed at 29 days of age, and predominated at 32 days (Fig. 1A). Thereafter, follicles progressed through anagen III (33 days) and anagen IV (34-35 days). In live animals, the mean age at which new hair was first observed emerging from the dorsal skin (anagen VI) was day $36 \pm 0 \cdot 2$, although some anagen III-V follicles persisted until 38 days of age (Fig. 1B).
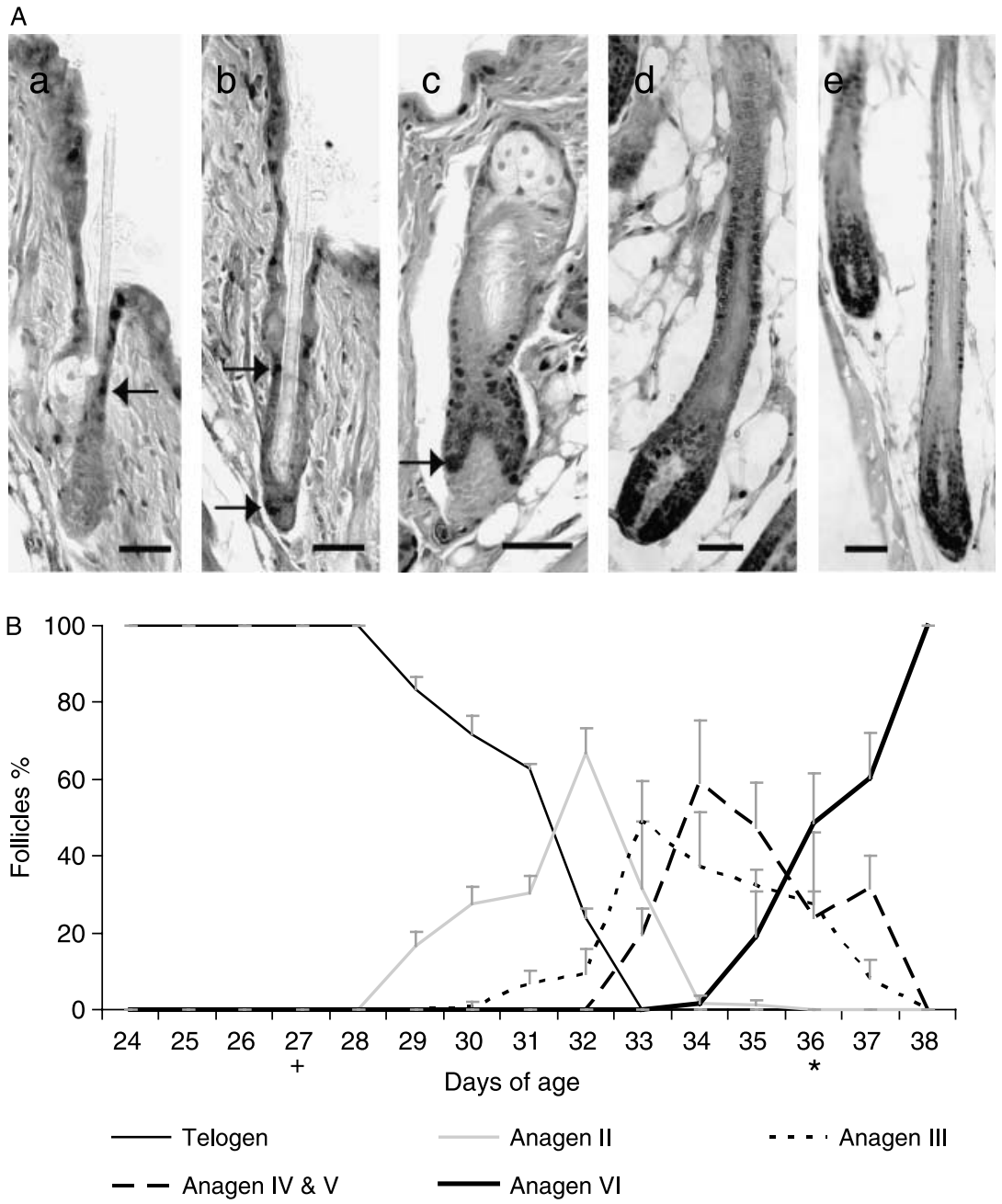

Figure 1 Histological characterisation of the first hair replacement cycle. Results for the dorsal skin of untreated female Balb/c mice are shown. (A) PCNA immunolocalisation in hair follicles: (a) no PCNA is detected in a lower telogen follicle (26 days of age), (b) induction of anagen is characterised by presence of PCNA in the hair germ during anagen I ( 27 days of age), (c) proliferating cells of the germinal epithelium in an anagen II follicle (29 days of age), (d) anagen III follicle (33 days of age), (e) anagen IV follicle (33 days of age). Arrows indicate PCNA localisation in nuclei. Bars $=50 \mu \mathrm{m}$ (B) Summary of histological assessment showing percentage of dorsal hair follicles in various stages of the hair cycle. Data represent the mean proportions of follicles in each stage, obtained by assessing $>30$ follicles from each of three mice per time point. Error bars indicate S.E.M. + Indicates mean age when PCNA immunohistochemical labelling within hair germ first occurs and * indicates mean age when hair is first observed emerging through the skin surface. 
Circulating prolactin levels changed while the skin was passing through this follicle growth cycle. Mean prolactin concentration in untreated females was $17 \pm 10 \mathrm{ng} / \mathrm{ml}$ at $15-$ 18 days of age. Prolactin concentration then increased, rapidly at first and then more slowly to $76 \pm 20 \mathrm{ng} / \mathrm{ml}$ at 39 days of age $(P<0 \cdot 01 ;$ Fig. $2 \mathrm{~A})$. Thus, changes in circulating prolactin preceded changes in hair cycle phase.

The expression of PRLR and prolactin in skin also changed during the follicle cycling period. Expression in dorsal skin of three isoforms of PRLR was assessed using real time PCR (Fig. 2B). Levels of PRLRL mRNA were low throughout the telogen period preceding the first hair replacement cycle. At 33 days of age, expression began increasing to reach maximal levels during anagen (36-39 days). Similar expression profiles of PRLRS2 and PRLRS3 mRNA were found, with levels increasing during early anagen. Compared with the PRLRL isoform, 3-4 more
PCR cycles were required to amplify the truncated receptor isoforms, suggesting that they are expressed at lower levels in skin. Expression of prolactin mRNA in the skin was similarly depressed during telogen and then increased until late anagen.

Plasma prolactin and pelage replacement in prolactin-manipulated mice

To directly determine the effect of prolactin on follicle cycling, endogenous prolactin was suppressed with BRC and replaced with exogenous prolactin administered at different ages. BRC suppressed circulating prolactin in implanted mice $(6 \pm 4 \mathrm{ng} / \mathrm{ml})$ as compared with untreated controls $(84 \pm$ $14 \mathrm{ng} / \mathrm{ml} ; P<0 \cdot 001)$. Osmotic pumps delivering $500 \mu \mathrm{g} /$ day ovine prolactin resulted in mean ovine prolactin levels of $353 \pm 81 \mathrm{ng} / \mathrm{ml}$, measured at the time of pump removal.
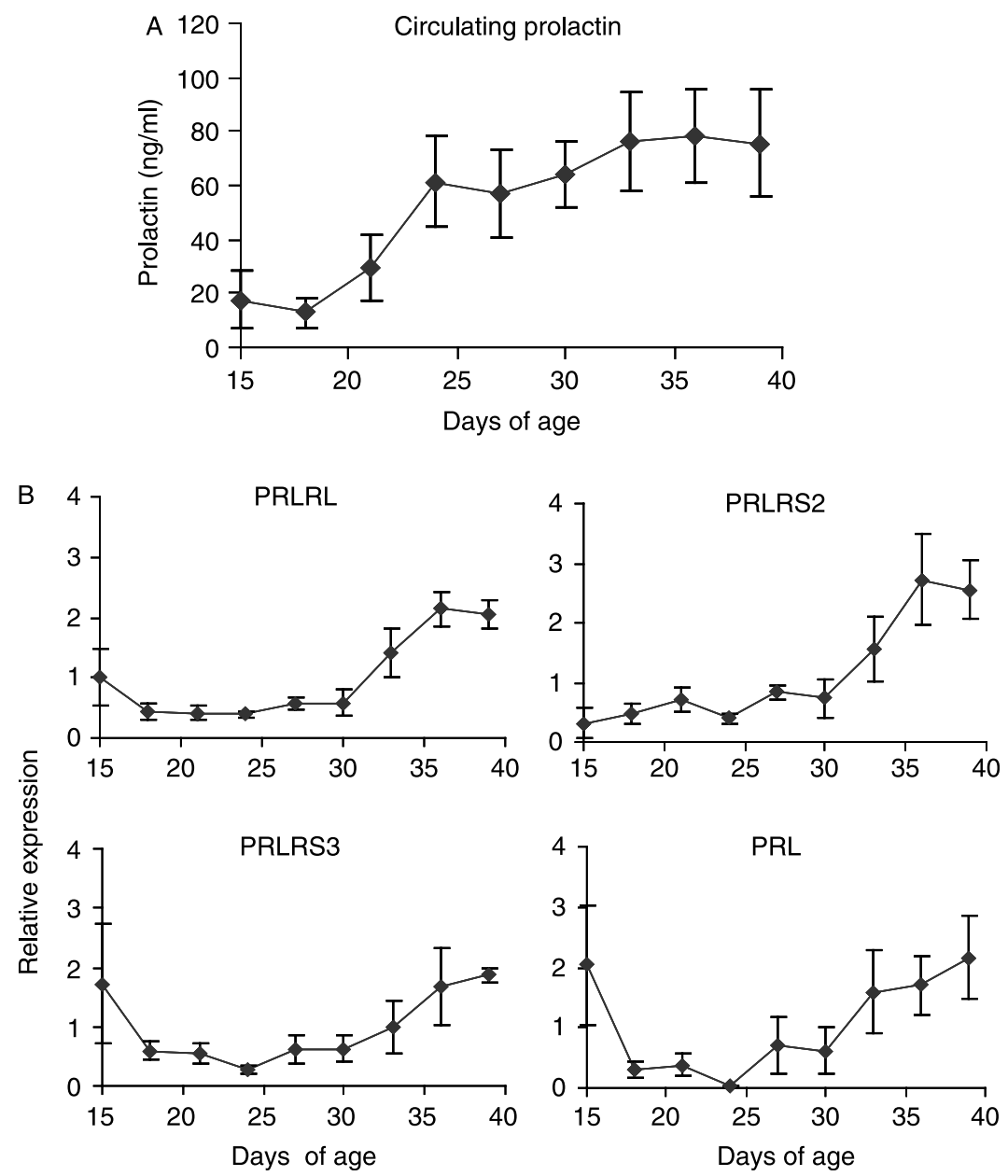

Figure 2 Characterisation of prolactin signalling capability during the first hair replacement cycle. Results for untreated female Balb/c mice are shown. (A) Plasma prolactin concentrations were measured by radioimmunoassay. (B) Relative expression of mRNA encoding PRLR isoforms and prolactin ligand was assessed in dorsal skin by real time PCR. Expression levels are normalised to ribosomal 18S rRNA levels. Error bars indicate S.E.M. of four animals per time point. 
In the mice receiving BRC implants at 15 days, hair regrowth first appeared in the axillary regions at $28 \cdot 2 \pm$ $0 \cdot 2$ days of age. This is 3 days earlier than axillary follicles of untreated controls $(31 \cdot 1 \pm 0 \cdot 2$ days of age; $P<0 \cdot 01$; Fig. 3$)$. When the implants were not inserted until 22 days of age, hair regrowth $(31.5 \pm 0.6$ days of age) was similar to controls. A similar trend was observed in the dorsal region. Mice receiving $\mathrm{BRC}$ at 15 days of age had earlier hair regrowth than controls $(32 \cdot 8 \pm 0 \cdot 4$ vs $36 \cdot 0 \pm 0 \cdot 4$ days of age $P<0 \cdot 001)$, but the age of hair emergence in the mice receiving BRC at 22 days was intermediate $(33 \cdot 5 \pm 0 \cdot 5$ days of age).

Axillary region

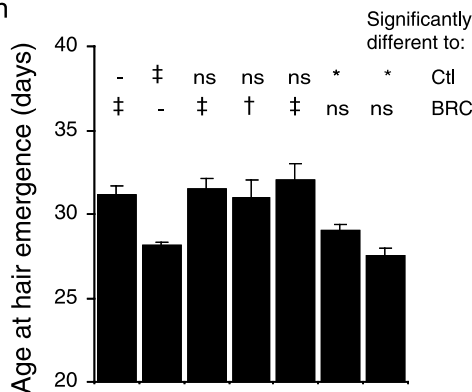

\section{Dorsal region}

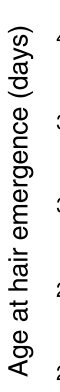

Start of BRC treatment (days) Start of prolactin treatment (days) Duration of prolactin treatment (days) $n=$

Figure 3 Effects of varying prolactin treatments on hair follicle cycling. The ages at which new hair first emerges are shown. New hairs are seen initially in the axillary region and subsequently in dorsal skin. Bromocriptine and prolactin treatment regimes are summarised below the charts. The number of animals in each treatment group is also shown. As compared with untreated controls $(\mathrm{Ctl})$, mice receiving bromocriptine (BRC) at 15 days of age exhibited new hair emergence at a younger age in both body sites. However, if BRC treatment did not commence until 22 days of age, the advanced hair regrowth did not occur in the axilla. The age of hair emergence when mice were treated with BRC at day 15 and then received prolactin-releasing minipumps (500 $\mu$ g per day) at 18,22 or 26 days of age, lasting for 3 or 14 days duration is also shown. Prolactin treatment for 3 days commencing at 18 days abrogated the premature regrowth induced by earlier BRC treatment. Prolactin (Prl) treatment for longer durations (14 days) resulted in delayed hair regrowth. Error bars indicate S.E.M. Treatment groups that are significantly different to either untreated controls (Ctl) or to BRC administered at 15 days are indicated: ${ }^{*} P<0 \cdot 05 ;{ }^{\dagger} P<0 \cdot 01 ;{ }^{\ddagger} P<0 \cdot 001 ;$ ns, not significant.
In the mice receiving exogenous prolactin as well as BRC, hair regrowth was delayed in comparison with mice receiving only BRC. Thus, in dorsal skin, the premature hair regrowth in mice treated with BRC alone (at $32 \cdot 8 \pm 0 \cdot 4$ days of age; $P<0.01)$ was reversed by the administration of prolactin for 3 days, commencing at 18 days of age (regrowth at $35 \pm$ $0 \cdot 1$ days of age; $P<0 \cdot 05)$. Furthermore, if prolactin treatment was extended to 14 days, dorsal hair cycles occurred later still $(39 \cdot 5 \pm 0 \cdot 5$ days of age; $P<0 \cdot 01)$. Similarly, late dorsal regrowth was observed if prolactin treatment commenced at 22 days of age $(39 \cdot 3 \pm 0 \cdot 5$ days of age; $P<0 \cdot 001)$, but not if infusion commenced at 26 days $(32 \cdot 5 \pm 0 \cdot 5$ days of age). In axillary skin, prolactin only reversed the effect of BRC if treatment commenced at 15 days. Bearing in mind that hair regrowth in the axilla normally precedes that in the dorsum, these results indicate that prolactin only has an effect when administered sufficiently early in telogen.

The effect of altered prolactin signalling was also investigated by treating mice with domperidone, which increased circulating prolactin to $142 \pm 30 \mathrm{ng} / \mathrm{ml}$, compared with untreated control levels of $89 \pm 8 \mathrm{ng} / \mathrm{ml}(P<0 \cdot 01)$. The treatment between

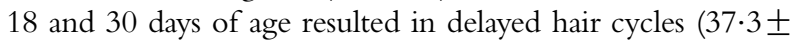
$0 \cdot 3$ days of age) as compared with mice receiving the diluent only (35.3 \pm 0.7 days of age; $P<0 \cdot 05)$. This result is evidence that the altered hair cycling seen in mice treated with exogenous prolactin was not an artefact caused by ovine prolactin exerting non-physiological bioactivity in a murine host.

As the timing of prolactin treatments that affected hair cycles coincided with weaning, we tested whether the age of weaning influenced the onset of anagen. Mice weaned at 18 days underwent hair cycles at the same age as littermates weaned at 24 days of age (dorsal hair emergence at 34.0 $\pm 0 \cdot 6$ and $34 \cdot 3 \pm 0.3$ days of age respectively). This suggests that any stress or hormonal changes associated with early weaning were without measurable hair growth consequences.

\section{Grafting PRLR knockout skin onto scid host mice}

To determine whether prolactin effects on hair cycling are mediated by direct action of the hormone on hair follicles, skin from PRLR knockout mice and wild-type littermates was grafted onto immunodeficient hosts. Each host received two grafts, one of knockout skin and another of wild-type skin (Fig. 4A), allowing direct comparison of the two genotypes in a normal endocrine setting. All the 20 pairs of grafts were successfully established on scid mouse hosts. In general, grafted mouse skin exhibited three anagen phases over 15 weeks following transplantation, interspersed with periods of telogen (Fig. 4B). Previous studies in our laboratory have shown that the initial hair cycle is induced by the surgical manipulation. It consistently occurs 1020 days after the grafting procedure and does not correspond to normal hair cycle times in either hosts or donors. This initial grafting-induced anagen is represented in Fig. 4B by grey bars. 


\section{A}
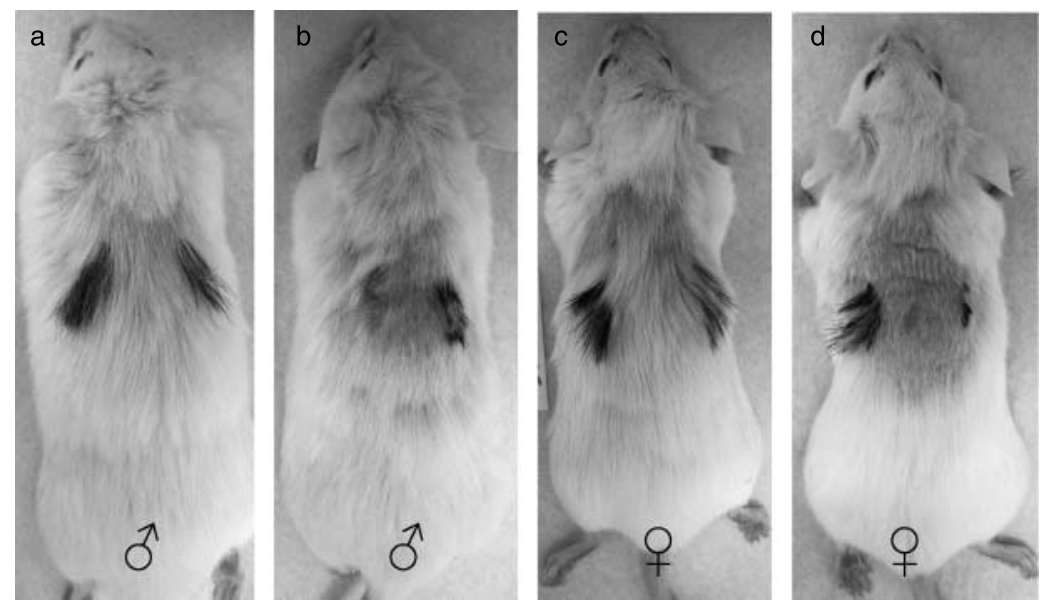
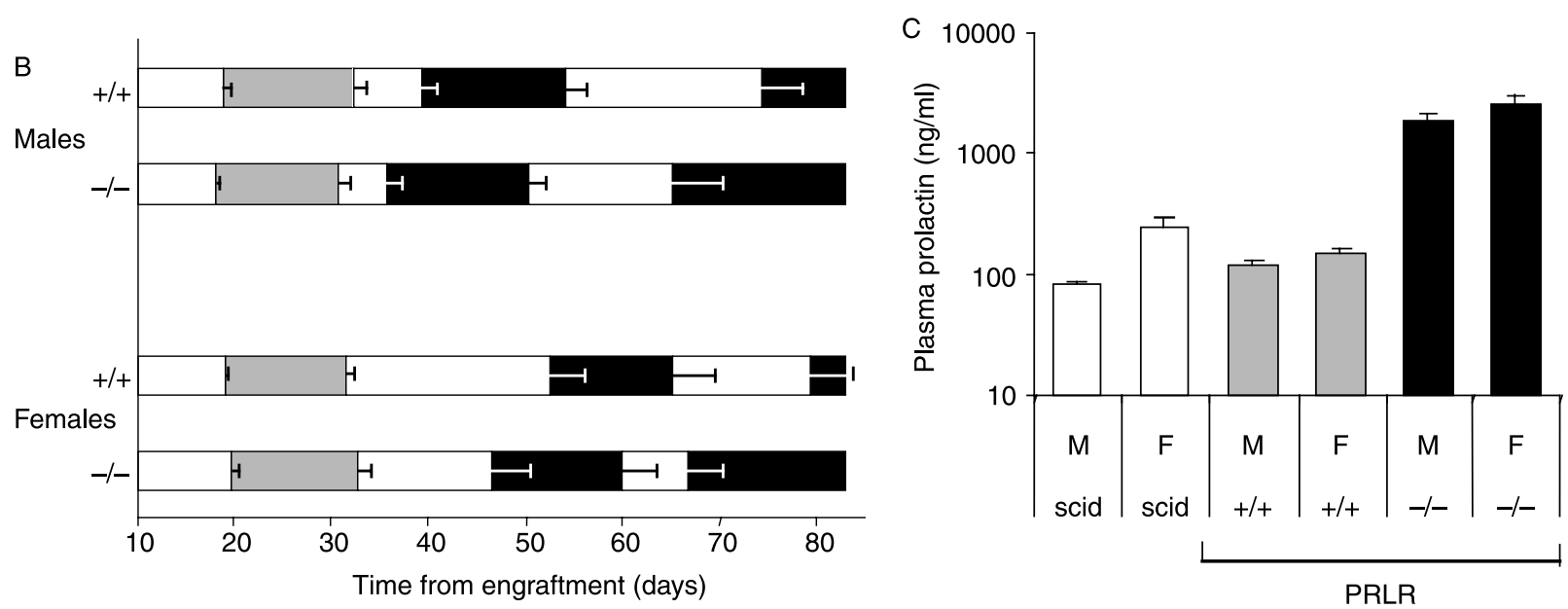

Figure 4 Hair growth in skin grafts from PRLR knockout $(-/-)$ and wild-type $(+/+)$ mice. (A) Scid mice carrying grafts from closely related PRLR knockout (left scapular) and wild-type (right scapular) donor mice. Pigmented hair growing from the grafted skin is readily visible against the white coat of the hosts. Representative males (a and b) and females (c and d) at the conclusion of the experiment, 89 days after engraftment are shown. Hair is near to fully grown in mice a and c. Differences in hair growth between graft genotypes were revealed by shaving the dorsal skin, including the graft sites, at 4-day intervals, as seen in mouse d. (B) All grafts exhibited a hair growth cycle at 18-20 days after surgery (grey bars). Subsequent cycles (black bars) in knockout grafts occurred in advance of sex matched wild-type grafts $(P<0 \cdot 05)$. (C) Plasma prolactin concentration in donor PRLR $-/-$ mice is grossly elevated as compared with PRLR $+/+$ and scid recipients $(P<0 \cdot 001)$. Error bars indicate S.E.M.

The PRLR genotype had no effect on the timing of the grafting-induced hair cycle, but subsequent cycles were advanced in knockout skin. Hair growth was also less well synchronised within knockout grafts, and there was a marked sex difference in cycle timing (Fig. 4B). The start of the second growth period in knockout grafts preceded the wild type by $5.9 \pm 1.9$ days $(P<0 \cdot 01)$ in females and $3 \cdot 4 \pm 1 \cdot 8$ days $(P<0 \cdot 05)$ in males. For both sexes, the length of time that no hair growth was observed was also lower in knockout compared with wild-type grafts (Fig. 4B; $P<0 \cdot 05$ ). Thus, there was a shorter duration of telogen in the knockout as compared with wild-type skin, even when both were exposed to the same set of systemic factors. Circulating prolactin concentrations in scid and wild-type $129 \mathrm{~Sv}$ mice (i.e. the PRLR knockout background) were similar, but both were tenfold lower than seen in PRLR knockout (Fig. 4C).

\section{Discussion}

The phenotype of PRLR knockout mice implicated prolactin as an endocrine regulator of hair cycle timing. In 
this study, we showed that changes in circulating prolactin levels were associated with progression through the hair cycle and with changes in prolactin signalling status in skin. Hair follicle cycling in young Balb/c mice was synchronised, with dorsal follicles entering catagen at 17-19 days of age and then remaining in telogen until around day 26. In the same animals, circulating prolactin was relatively low for the first 3 weeks after birth, in agreement with previous data (Barkley 1979), but began increasing from day 18 . Thus, changes in circulating prolactin are associated with the transition into catagen, consistent with the possibility that prolactin has a causal role in inhibiting hair growth. We confirmed this role by showing that re-entry to anagen was advanced when circulating prolactin secretion was suppressed with BRC, but delayed when mice were treated with exogenous prolactin.

In unmanipulated mice, expression of the PRLR and prolactin genes in skin also changed through the hair cycle, but these changes occurred later than the changes in circulating prolactin. Thus, expression levels were low during telogen and early anagen but increased markedly by the 5 th week of age, in accordance with previous studies that also report higher levels of PRLR transcripts during anagen (Craven et al. 2001, Foitzik et al. 2003). The lagged response of both full length and short form PRLR mRNAs in relation to circulating prolactin may reflect ligand-mediated receptor upregulation (Soboleva et al. 2005) as has been reported in a number of organs including kidney, liver, mammary gland (Barash et al. 1986) and adipose depots (Ling et al. 2000), as well as skin (Nixon et al. 2002). Assuming protein translation occurs, a functional role has yet to be ascribed for prolactin synthesised within the integument, but maintenance of tonic signalling during periods of low pituitary secretion has been postulated (Ben-Jonathan et al. 1996). Overall, these results suggest that the sensitivity of skin to systemic prolactin changes throughout the hair cycle.

More generally, hair cycling is likely to be influenced by prolactin signalling status within the skin as well as circulating prolactin levels per se. The low prolactin signalling potential in mouse pups, due to low concentrations of both circulating ligand and cellular receptors, may underlie the brevity of the first telogen phase. Subsequent telogen periods become progressively longer (Ebling et al. 1991), against a background of increasing prolactin and increasing PRLR expression.

The effects of both BRC and prolactin administration were influenced by the time at which treatment commenced. BRC affected hair regrowth on the axilla only at 15 days of age, but on the dorsum at 15 and 22 days of age. Similarly, prolactin administration starting at 18 and 22 days of age reversed the effects of BRC on dorsal follicle cycling, but axillary follicles were only affected by prolactin treatment from 18 days. These dorso-ventral differences in response correspond to the difference between body sites in the timing of the hair growth wave. Thus, the period of sensitivity to altered prolactin signalling appears to be directly related to the follicle growth cycle, with only telogen follicles able to respond. Once follicles enter early anagen, they exhibit a commitment to continued growth that cannot be altered by perturbing prolactin signalling. Our results are diagrammatically summarised in Fig. 5.

It is likely that follicles become resensitised to prolactin later in anagen. Prolactin has been shown to inhibit the growth of anagen follicles in mice (Foitzik et al. 2003) and in sheep (Pearson et al. 1999). Prolactin is able to hasten catagen in murine (Foitzik et al. 2003) and human (Foitzik et al. 2006) skin organ culture. Hence, the inhibitory effect of prolactin can be seen in species with both seasonal and non-seasonal hair cycling patterns. Furthermore, prolactin is inhibitory at different stages of the follicle cycle, with the ability to reduce hair length (Craven et al. 2001) or shorten anagen, as demonstrated in sheep, or to lengthen telogen as we have demonstrated in $\mathrm{Balb} / \mathrm{c}$ mice.

Hair regrowth affected by BRC was not as premature as that observed in PRLR-gene disrupted mice (Craven et al. 2001). This difference might reflect residual prolactin due to
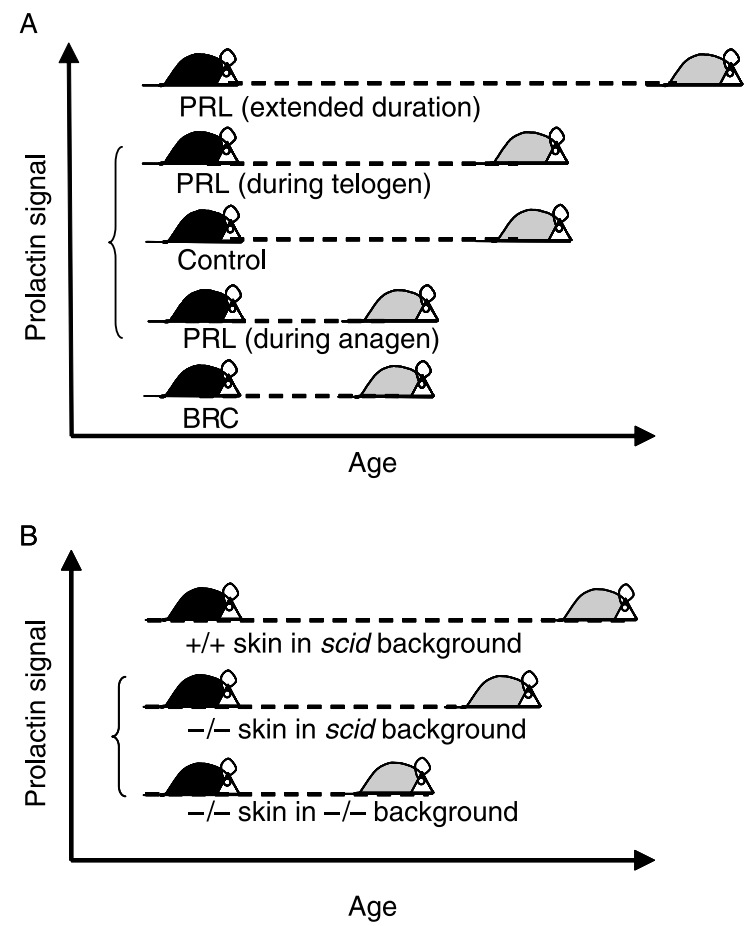

Figure 5 Schematic representation of hair replacement patterns in mouse skin with varying prolactin signalling capability. Progression from their initial hair coat (shown as black mouse) to their subsequent hair coat (shown as grey mouse). (A) Bromocriptine (BRC) treated mice underwent hair cycles earlier than untreated controls, or those also receiving prolactin ( $\mathrm{Prl}$ ) during telogen for 3 days. PRL-treatment during early anagen had no effect while those BRC-treated mice receiving PRL for 14 days had delayed hair growth beyond that observed in controls. (B) Hair replacement in PRLR $+/+$ and PRLR $-/-$ skin grafted onto immunodeficient scid mice. Hair cycles in PRLR - / - explants occur earlier than PRLR $+/+$ explants. However, note that the difference in the duration of telogen appears greater between entire PRLR $-/-$ and PRLR $+/+129$ Sv mice (Craven et al. 2001) than in their respective skin transplants onto scid mice. 
incomplete suppression or locally synthesised prolactin, which is not suppressed by BRC (Ben-Jonathan et al. 1996). It is also possible that a BRC-induced mechanism unrelated to prolactin is acting to influence the induction of anagen. For example, the pro-opiomelanocortin system (Paus et al. 1999) may be upregulated via activation of BRCsensitive dopamine receptors (Farrell et al. 1992). However, prolactin-negative effects of BRC on hair cycles were consistent with other manipulations of prolactin.

Removal of prolactin through ablation of the pituitary gland has been shown previously to advance hair cycles in rats (Mohn 1958, Ebling et al. 1991). However, this effect was attributed to the withdrawal of adrenal and gonadal steroids. Advanced hair follicle activity is also stimulated by hypophysectomy, gonadectomy, adrenalectomy and administration of thyroxine (Ebling et al. 1991). In general, these treatments need to be carried out well in advance of the timing of expected hair eruption, which is also consistent with sensitivity during telogen and some degree of follicle growth autonomy after the initiation of anagen. Similarly, glucocorticoid treatments can block follicle regrowth, but only if applied prior to anagen induction (Stenn et al. 1993).

PRLR-deficient mice have grossly elevated levels of circulating prolactin due to ablation of the feedback signalling that regulates the pituitary lactotrophs (Grattan et al. 2001). However, the regulation of other hormones is also perturbed in these mice. For example, circulating concentrations of oestradiol are lower in female knockout mice at oestrous ( $37 \mathrm{pg} / \mathrm{ml}$ compared with $53 \mathrm{pg} / \mathrm{ml}$ in wild-type mice) (Clement-Lacroix et al. 1999). Oestradiol has been shown to have a direct inhibitory effect on hair growth cycles (Ebling et al. 1991), and oestradiol receptors have been located in the dermal papillae of telogen follicles (Oh \& Smart 1996). Similarly, PTH is increased (Clement-Lacroix et al. 1999) and has been implicated previously in hair cycle regulation (Schilli et al. 1997).

Thus, prior to this study, it was unclear whether prolactin exerted its effect directly on the follicle or indirectly by influencing alternative endocrine pathways (Craven et al. 2001). By transplanting skin lacking prolactin-signalling capability to a normal endocrine environment, and observing that a shorter telogen period is retained, we have demonstrated that prolactin acts via a direct mode of action. Although considerable variation in follicle behaviour occurred, with respect to both follicles within and between grafts, differences between genotypes and sexes were evident. Variation in hair growth between males and females, even in PRLR-deficient mice, may arise due to systemic differences related to the sex of the host. Furthermore, these transplantation experiments do not exclude the possibility that indirect effects of PRLR ablation exert an additional intra-cutaneous influence on follicle cycling. However, the results demonstrate a skin-autonomous effect, and given the strong localisation of PRLR and PRLR mRNA in the outer root sheath and secondary hair germ of hair follicles
(Craven et al. 2001, Foitzik et al. 2003), it is reasonable to conclude that prolactin acts directly on the follicle.

In contrast to suppressive effects of oestradiol (Oh \& Smart 1996, Chanda et al. 2000), glucocorticoids (Stenn et al. 1993) and ACTH (Ebling et al. 1991), the immunosuppressant drug cyclosporin A (CsA) is a known hair growth stimulant that can induce telogen follicles into anagen prematurely (Paus et al. 1989, Maurer et al. 1997). Although the mechanism of its action within the hair follicle is unclear, CsA is known to complex with cyclophillins, which interact directly with the PRLR and its signal transduction factors. These molecules have propyl isomerase activity that induces structural changes within the PRLR intracellular domain and, along with further interactions with JAK2 (cyclophillin A) (Syed et al. 2003) and Stat5 and protein inhibitor of activated stat (PIAS) (cyclophillin B) (Rycyzyn \& Clevenger 2002), are able to potentiate prolactin-induced gene transcription. Therefore, follicle stimulatory actions of CsA, which possibly arise from decreased PRLR signal transduction, are consistent with the inhibitory nature of prolactin reported here.

At the cellular level, the function of prolactin within the follicle remains unclear. Different mammalian cells are known to exhibit a variety of responses to prolactin stimulation, including changes in cell proliferation, migration and apoptosis (Bole-Feysot et al. 1998, Clevenger et al. 2003). In follicles, PRLR have been localised to keratinocytes in the middle of the follicle outer root sheath (Craven et al. 2001, Nixon et al. 2002, Foitzik et al. 2003), up to and including the bulge region. The bulge region is thought to contain a reservoir of stem cells, the daughters of which migrate down the outer root sheath to repopulate the rapidly proliferating germinal matrix in the lower follicle (Oshima et al. 2001, Stenn \& Paus 2001). Germinal matrix cells then differentiate to form the hair shaft. Catagen is thought to be induced, at least in part, by the loss of proliferative activity in the germinal matrix. We therefore speculate that prolactin may exert its effects on follicle cycling by modulating the migration of precursor cells in the outer root sheath. This could be achieved by regulating cell adhesion factors such as the cadherins (Sultan et al. 2005) or by Stat3-responsive factors (Kira et al. 2002), both of which are necessary for continuous hair cycling (Sano et al. 1999, Young et al. 2003). Such inhibition of migration would deprive the germinal matrix of cells with proliferative potential, thereby either extending the telogen phase or terminating anagen.

In summary, we have demonstrated that prolactin acts directly within the skin to modulate the timing and duration of telogen. Follicles are responsive to prolactin signalling only during some phases of the growth cycle. This point has implications for the design of experiments involving prolactin and hair growth, and may explain the failure of some previous attempts to alter hair cycles by increasing circulating prolactin. The influence of prolactin on human follicle growth is becoming increasingly recognised (Orfanos \& Hertel 1988, Paus 1991, Krause et al. 2000, Alonso \& Rosenfield 2003, Foitzik et al. 2006). The results of our experiments suggest 
the potential for new strategies to address human hair growth disorders involving perturbed follicle cycling, including telogen effluvium and hirsutism (Orfanos \& Hertel 1988).

\section{Acknowledgements}

The authors thank Steven Gordon for the mRNA extraction and purification, Janet Wildermoth for assistance with the radioimmunoassays and Dr Neil Cox for the statistical analyses. Dr Nick Rufaut made helpful comments on the manuscript. The ovine and murine prolactin RIA reagents were supplied by the National Institute of Diabetes and Kidney Diseases. This research was funded by the New Zealand Foundation for Research, Science and Technology. The authors declare that there is no conflict of interest that would prejudice the impartiality of this scientific work.

\section{References}

Alonso LC \& Rosenfield RL 2003 Molecular genetic and endocrine mechanisms of hair growth. Hormone Research 60 1-13.

Barash I, Madar Z \& Gertler A 1986 Short-term regulation of prolactin receptors in the liver, mammary gland and kidney of pregnant and lactating rats infused with ovine prolactin or human growth hormone. Molecular and Cellular Endocrinology 46 235-244.

Barkley MS 1979 Serum prolactin in the male mouse from birth to maturity. Journal of Endocrinology 83 31-33.

Ben-Jonathan N, Mershon J, Allen D \& Steinmetz R 1996 Extrapituitary prolactin: distribution, regulation, functions, and clinical aspects. Endocrine Reviews 17 639-669.

Bole-Feysot C, Goffin V, Edery M, Binart N \& Kelly PA 1998 Prolactin (PRL) and its receptor: actions, signal transduction pathways and phenotypes observed in PRL receptor knockout mice. Endocrine Reviews 19 225-268.

Chanda S, Robinette CL, Couse JF \& Smart RC 2000 17Beta-estradiol and ICI-182,780 regulate the hair follicle cycle in mice through an estrogen receptor-alpha pathway. American Journal of Physiology, Endocrinology and Metabolism 278 E202-E210.

Clement-Lacroix P, Ormandy C, Lepescheux L, Ammann P, Damotte D, Goffin V, Bouchard B, Amling M, Gaillard-Kelly M, Binart N et al. 1999 Osteoblasts are a new target for prolactin: analysis of bone formation in prolactin receptor knockout mice. Endocrinology 140 96-105.

Clevenger CV, Furth PA, Hankinson SE \& Schuler LA 2003 The role of prolactin in mammary carcinoma. Endocrine Reviews 24 1-27.

Craven AJ, Ormandy CJ, Robertson FG, Wilkins RJ, Kelly PA, Nixon AJ \& Pearson AJ 2001 Prolactin signaling influences the timing mechanism of the hair follicle: analysis of hair growth cycles in prolactin receptor knockout mice. Endocrinology 142 2533-2539.

Dicks P, Russel AJF \& Lincoln GA 1994 The role of prolactin in the reactivation of hair follicles in relation to moulting in cashmere goats. Journal of Endocrinology 143 441-448.

Ebling FJ, Hale PA \& Randall VA 1991 Hormones and hair growth. In Physiology, Biochemistry and Molecular Biology of the Skin, edn 2, vol 1, pp 660-696. Ed. L Goldsmith, New York: Oxford University Press.

Emmens CW 1942 The endocrine system and hair growth in the rat. Journal of Endocrinology 3 64-78.

Farrell WE, Clark AJ, Stewart MF, Crosby SR \& White A 1992 Bromocriptine inhibits pro-opiomelanocortin mRNA and ACTH precursor secretion in small cell lung cancer cell lines. Journal of Clinical Investigation 90 705-710.
Foitzik K, Krause K, Nixon AJ, Ford CA, Ohnemus U, Pearson AJ \& Paus R 2003 Prolactin and its receptor are expressed in murine hair follicle epithelium, show hair cycle-dependent expression, and induce catagen. American Journal of Pathology 162 1611-1621.

Foitzik K, Krause K, Conrad F, Nakamura M, Funk W \& Paus R 2006 Human scalp hair follicles are both a target and a source of prolactin, which serves as an autocrine and/or paracrine promoter of apoptosis-driven hair follicle regression. American Journal of Pathology 168 748-756.

Grattan DR, Xu J, McLachlan MJ, Kokay IC, Bunn SJ, Hovey RC \& Davey HW 2001 Feedback regulation of PRL secretion is mediated by the transcription factor, signal transducer and activator of transcription 5b. Endocrinology 142 3935-3940.

Kira M, Sano S, Takagi S, Yoshikawa K, Takeda J \& Itami S 2002 STAT3 deficiency in keratinocytes leads to compromised cell migration through hyperphosphorylation of p130(cas). Journal of Biological Chemistry 277 12931-12936.

Krause K, Foitzik K, Mecklenburg L \& Paus R 2000 Hair-cycle dependent expression of prolactin in human and mouse skin. Journal of Investigative Dermatology 115581 (Abstract 309).

Ling C, Hellgren G, Gebre-Medhin M, Dillner K, Wennbo H, Carlsson B \& Billig H 2000 Prolactin (PRL) receptor gene expression in mouse adipose tissue: increases during lactation and in PRL-transgenic mice. Endocrinology 141 3564-3572.

Loudon AS, Milne JA, Curlewis JD \& McNeilly ASA 1989 Comparison of the seasonal hormone changes and patterns of growth, voluntary food intake and reproduction in juvenile and adult red deer (Cervus elaphus) and Pere David's deer (Elaphurus davidianus) hinds. Journal of Endocrinology 122 733-745.

Martinet L, Allain D \& Weiner C 1984 Role of prolactin in the photoperiodic control of moulting in the mink (Mustela vison). Journal of Endocrinology 103 9-15.

Maurer M, Handjiski B \& Paus R 1997 Hair growth modulation by topical immunophilin ligands: induction of anagen, inhibition of massive catagen development, and relative protection from chemotherapy-induced alopecia. American Journal of Pathology 150 1433-1441.

McCloghry CE, Hollis DE, Foldes A, Rintoul AJ, Baker P, Vaughan JD, Maxwell CA, Kennedy JP \& Wynn PC 1993 The effects of exogenous melatonin and prolactin on wool follicle development in ovine foetal skin grafts. Australian Journal of Agricultural Research 44 993-1002.

Milner Y, Sudnik J, Filippi M, Kizoulis M, Kashgarian M \& Stenn K 2002 Exogen, shedding phase of the hair growth cycle: characterization of a mouse model. Journal of Investigative Dermatology 119 639-644.

Mohn MP 1958 In The Effects of Different Hormonal States on the Growth of Hair in Rats, pp 335-398. Eds W Montagna \& RA Ellis. New York: Academic Press.

Muller-Rover S, Handjiski B, van der Veen C, Eichmuller S, Foitzik K, McKay IA, Stenn KS \& Paus R 2001 A comprehensive guide for the accurate classification of murine hair follicles in distinct hair cycle stages. Journal of Investigative Dermatology 117 3-15.

Nixon AJ 1993 A method for determining the activity state of hair follicles. Biotechnic and Histochemistry 68 316-325.

Nixon AJ, Choy VJ, Parry AL \& Pearson AJ 1993 Fibre growth initiation in hair follicles of goats treated with melatonin. Journal of Experimental Zoology 267 47-56.

Nixon AJ, Ford CA, Wildermoth JE, Craven AJ, Ashby MG \& Pearson AJ 2002 Regulation of prolactin receptor expression in ovine skin in relation to circulating prolactin and wool follicle growth status. Journal of Endocrinology 172 605-614.

Oh HS \& Smart RC 1996 An estrogen receptor pathway regulates the telogen-anagen hair follicle transition and influences epidermal cell proliferation. PNAS 93 12525-12530.

Orfanos CE \& Hertel H 1988 Disorder of hair growth in hyperprolactinemia. Zeitschrift für Hautkrankheiten 63 23-26.

Ormandy CJ, Camus A, Barra J, Damotte D, Lucas B, Buteau H, Edery M, Brousse N, Babinet C, Binart N et al. 1997 Null mutation of the prolactin receptor gene produces multiple reproductive defects in the mouse. Genes and Development 11 167-178. 
Oshima H, Rochat A, Kedzia C, Kobayashi K \& Barrandon Y 2001 Morphogenesis and renewal of hair follicles from adult multipotent stem cells. Cell $104233-245$.

Parry AL, Craven AJ, Nixon AJ \& Pearson AJ 1995 The microanatomy, cell replication, and keratin gene expression of hair follicles during a photoperiod-induced growth cycle in sheep. Acta Anatomica 154 283-299.

Paus R 1991 Does prolactin play a role in skin biology and pathology? Medical Hypotheses 36 33-42.

Paus R, Stenn KS \& Link RE 1989 The induction of anagen hair growth in telogen mouse skin by cyclosporine A administration. Laboratory Investigation 60 365-369.

Paus R, Botchkarev VA, Botchkareva NV, Mecklenburg L, Luger T \& Slominski A 1999 The skin POMC system (SPS). Leads and lessons from the hair follicle. Annals of the New York Academy of Sciences 885 350-363.

Pearson AJ, Parry AL, Ashby MG, Choy VJ, Wildermoth JE \& Craven AJ 1996 Inhibitory effect of increased photoperiod on wool follicle growth. Journal of Endocrinology 148 157-166.

Pearson AJ, Ashby MG, Wildermoth JE, Craven AJ \& Nixon AJ 1999 Effect of exogenous prolactin on the hair growth cycle. Experimental Dermatology 8 358-360.

Rycyzyn MA \& Clevenger CV 2002 The intranuclear prolactin/cyclophilin B complex as a transcriptional inducer. PNAS 99 6790-6795.

Sano S, Itami S, Takeda K, Tarutani M, Yamaguchi Y, Miura H, Yoshikawa K, Akira S \& Takeda J 1999 Keratinocyte-specific ablation of Stat3 exhibits impaired skin remodeling, but does not affect skin morphogenesis. EMBO Journal 18 4657-4668.

Schilli MB, Ray S, Paus R, Obi-Tabot E \& Holick MF 1997 Control of hair growth with parathyroid hormone. Journal of Investigative Dermatology 108 928-932.
Soboleva TK, Vetharaniam I, Nixon AJ, Montenegro R, Pearson AJ \& Sneyd J 2005 Mathematical modelling of prolactin-receptor interaction and the corollary for prolactin receptor gene expression in skin. Journal of Theoretical Biology 234 289-298.

Stenn KS \& Paus R 2001 Controls of hair follicle cycling. Physiological Reviews 81 449-494.

Stenn KS, Paus R, Dutton T \& Sarba B 1993 Glucocorticoid effect on hair growth initiation: a reconsideration. Skin Pharmacology 6 125-134.

Sultan AS, Xie J, LeBaron MJ, Ealley EL, Nevalainen MT \& Rui H 2005 Stat5 promotes homotypic adhesion and inhibits invasive characteristics of human breast cancer cells. Oncogene 24 746-760.

Syed F, Rycyzyn MA, Westgate L \& Clevenger CV 2003 A novel and functional interaction between cyclophilin $\mathrm{A}$ and prolactin receptor. Endocrine 20 83-90.

Thompson DL Jr. Hoffman R \& DePew CL 1997 Prolactin administration to seasonally anestrous mares: reproductive, metabolic, and hair-shedding responses. Journal of Animal Science 75 1092-1099.

Young P, Boussadia O, Halfter H, Grose R, Berger P, Leone DP, Robenek H, Charnay P, Kemler R \& Suter U 2003 E-cadherin controls adherens junctions in the epidermis and the renewal of hair follicles. EMBO Journal 22 5723-5733.

Received in final form 16 August 2006 Accepted 22 August 2006 